\title{
HYBRID SWITCHING CONTROLLER DESIGN FOR THE MANEUVERING AND TRANSIT OF A TRAINING SHIP
}

\author{
MIROSŁAW TOMERA ${ }^{a}$ \\ ${ }^{a}$ Department of Ship Automation \\ Gdynia Maritime University, ul. Morska 81-87, 81-225 Gdynia, Poland \\ e-mail: m.tomera@we.am.gdynia.pl
}

\begin{abstract}
The paper presents the design of a hybrid controller used to control the movement of a ship in different operating modes, thereby improving the performance of basic maneuvers. This task requires integrating several operating modes, such as maneuvering the ship at low speeds, steering the ship at different speeds in the course or along the trajectory, and stopping the ship on the route. These modes are executed by five component controllers switched on and off by the supervisor depending on the type of operation performed. The desired route, containing the coordinates of waypoints and tasks performed along consecutive segments of the reference trajectory, is obtained by the supervisory system from the system operator. The former supports switching between component controllers and provides them with new set-points after each change in the reference trajectory segment, thereby ensuring stable operation of the entire hybrid switching controller. The study also presents designs of all controller components, which are done using a complex mathematical model of the selected ship, after its simplification depending on the type of controller. The developed control system was tested on the training ship Blue Lady and used to train captains at the Ship Handling Research and Training Center near Iława in Poland. The conducted research involved an automatic movement of the ship from one port to another. The performed transit route required the ship to leave the port, pass the water area, and berth at the port of destination. The study revealed good quality of the designed hybrid controller.
\end{abstract}

Keywords: hybrid switching controller, ship autopilot, desired route.

\section{Introduction}

Constantly increasing traffic on highways, in the air, and on the sea forces the need to search for new control algorithms enhancing safety, improving throughput, and reducing the latency of motion. In waterborne navigation, safety improvement is particularly important in increasingly crowded harbor passages and areas of constrictions on the sea. The target solution here seems to create a general ship traffic management system for all of these areas. The controller unit, situated on land, would plan the whole scenario of ships' movement within the controlled area, including the interaction between advanced autopilots installed on each ship. Such a system would be based on modern technologies, such as the global positioning system (GPS), digital maps of the sea, faster and more powerful computers, and larger numbers of better actuators (Godhavn et al., 1996). The implementation of this system would require, at first, developing a hybrid autopilot, to be installed on each ship sailing in the area. The onboard hybrid controller should be able to control the ship movement in various operating modes, from automatically maintaining the position in different weather conditions to maneuvering at high speeds. The route of the ship is usually adjusted using the so-called waypoints (Fossen, 2011). When defining these, we take into account characteristics such as weather conditions, obstacle avoidance, and mission planning (Lisowski, 2013).

The hybrid controller applied combines a number of simple controls in one system, with further switching between them by an automatic mechanism. Its design is based on well-known linear and nonlinear models which describe the dynamics of the process depending on the operating conditions. However, the use of a larger number of controller components and the resultant need to switch between them may lead to an instability of the entire control system. This problem is solved by introducing supervisory switching control (SSC), 
described by Hespanha (2001). The supervisory control strategy developed by that author assumes switching between linear and nonlinear controllers, depending on their operating conditions, with the aid of specially designed discrete logic which guarantees the stability of the entire system. Systems equipped with supervisory control switches can be connected with hybrid systems, as they consist of many continuous controllers and the discrete logic which enables switching between different controllers.

Hybrid systems are reactive systems in which both continuous and discrete states occur. The hybrid control system may be a switching circuit, the dynamic behavior of which is described by a finite number of dynamic models. These models usually comprise a set of differential or finite difference equations, complemented with a set of rules for switching between them. The switching rules are described by logical expressions, or by a discrete event system (DES) with a finite state machine, or by a Petri net. As a consequence, hybrid control systems contain two different types of subsystems. The first one reveals continuous dynamics, while the other has the dynamics of discrete events that interact with each other (Antsaklis and Nerode, 1989). These types of control are needed in some critical operating conditions when the controlled system is started or stopped, or changes the main planned operating modes. There is a common opinion that a single controller, designed to be used for each operating condition, would reduce the achievable quality and cause unpredictable behavior affecting the safety of operations performed in certain most critical areas (Balbis et al., 2007). The group of hybrid control systems includes a special class of switched systems, where each system comprises a collection of subsystems with a switching rule which specifies switching between them. Hybrid and switched control systems are now a very active area of research, especially in automotive industry (Lygeros et al., 1996; Kurt and Özgüner, 2013; Salehi et al., 2014; Taghavipour et al., 2015), aerospace industry (Pritchett et al., 2001; Kamgarpour et al., 2011) and many other domains (Xiang et al., 2010; Yang et al., 2012; Zhang et al., 2016).

In marine applications, hybrid control systems are most often used in dynamic ship positioning systems which have the ability to automatically switch between different controllers. Smogeli et al. (2004) proposed a hybrid thruster controller in dynamic positioning (DP) arrangement to control the thruster torque and estimate the torque loss at medium and high environmental disturbances caused by the action of wind, waves, and ocean currents.

The structure of the system with several continuous controllers and observers connected with them in pairs, based on the work of Hespanha (2001), was proposed by Nguyen et al. (2007) for hybrid steering in dynamic ship positioning. A supervisory switch controller was developed for dynamic positioning of the ship when the state of the sea changed from calm to extreme. The scope of correct operation of a single DP system was broadened by switching between different observer-controller pairs in response to the changing sea state. This solution was also used by Nguyen and Sorensen (2009) to maintain a constant position of the mooring ship. Moreover, an identical methodology (Nguyen et al., 2007), consisting in linking continuous controllers and observers in pairs, was used by the same authors in hybrid control which combined dynamic positioning, maneuvering and transit, as well as operations involving ship passing from transit to station keeping mode, as described by Nguyen et al. (2008).

The issue of hybrid control in dynamic ship positioning, discussed by Nguyen et al., (2007), was also examined by Brodtkorb et al., (2014), who used the structure of the hybrid control system described by Goedel et al. (2012). Their hybrid controller consisted of four component controllers, and switching between them took place when the state of the sea changed from calm to extreme. For this purpose, spectral frequency analysis of ship movements caused by sea waves was applied. Simulation tests were performed, and the quality of operation of the control system with a hybrid controller was compared with that of a single controller with adaptive wave filtering. Under extreme sea states, the control system with single control became unstable, while hybrid control still retained good control quality. Another application of a hybrid control system for dynamic ship positioning was presented by Tutturen and Skjetne (2015), who used a single multivariable controller PID in which the integral gain value was changed depending on the sea state.

This paper focuses on controlling the ship motion in different operating modes with the aid of a controller based on hybrid switching control theory. Various types of controllers which had been successfully used onboard ships were analyzed as possible executors of selected operating modes of ship control. This includes PID control systems, linear quadratic optimal control, and state feedback linearization. The reference ship trajectory consists of straight line segments connecting consecutive points of the passage route, with relevant operating modes of the controller assigned to them.

\section{Mathematical model of ship dynamics}

The mathematical model of ship dynamics with three degrees of freedom is considered (Fossen, 2011). The ship motion is described in the inertial frame fixed to the Earth's coordinate system $\left(X_{N}, Y_{N}\right)$, and the other coordinate frame $\left(X_{B}, Y_{B}\right)$ attached to the moving ship (Fig. 1). The state variables describing the ship motion are 


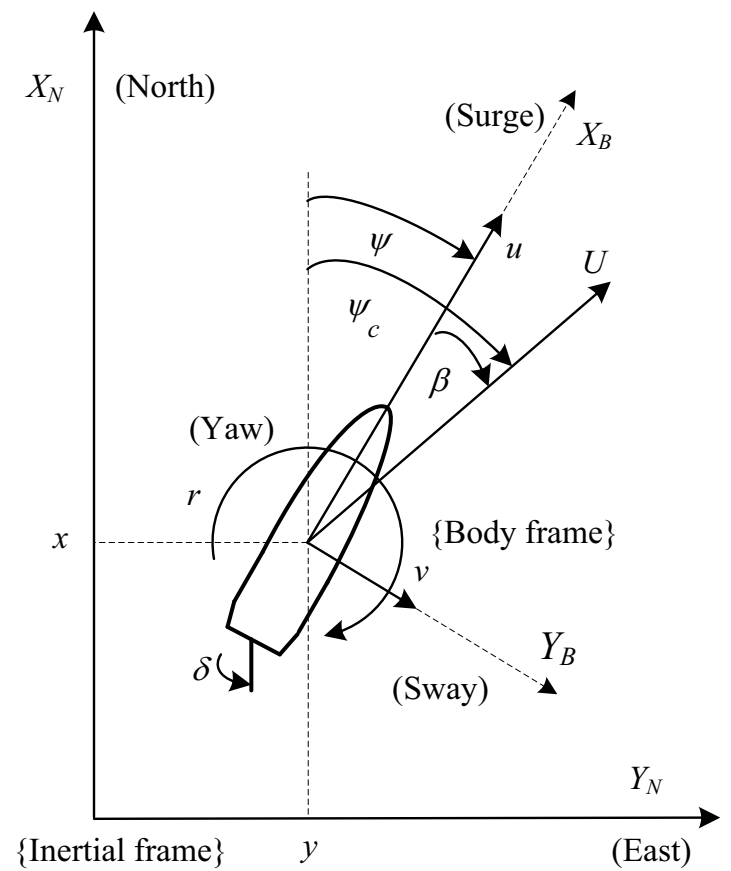

Fig. 1. Variables and coordination frames used to describe the ship motion in a horizontal plane, where $\psi_{c}$ is the course angle, $\delta$ is the rudder angle, $\beta$ is the slideship angle, and $U$ is the ship speed $\left(U=\sqrt{u^{2}+v^{2}}\right)$.

collected in two vectors $\boldsymbol{\eta}=[x, y, \psi]^{\mathrm{T}}$ and $\boldsymbol{\nu}=[u, v, r]^{\mathrm{T}}$, where $(x, y)$ are the ship position coordinates, $\psi$ is the ship heading, $(u, v)$ are the linear body fixed velocities (surge, sway), $r$ is the yawing rate (Bańka et al., 2015).

The Earth-fixed velocity vector defined in the inertial frame is related to the body-fixed velocity vector through the following kinematic relationship (Fossen, 2011):

$$
\dot{\boldsymbol{\eta}}=\boldsymbol{R}(\psi) \boldsymbol{\nu}
$$

where $\boldsymbol{R}(\psi)$ is the rotation matrix, calculated from the formula

$$
\boldsymbol{R}(\psi)=\left[\begin{array}{ccc}
\cos (\psi) & -\sin (\psi) & 0 \\
\sin (\psi) & \cos (\psi) & 0 \\
0 & 0 & 1
\end{array}\right]
$$

2.1. Mathematical model of Blue Lady. The physical model of Blue Lady is a replica made in scale 1:24 of a VLCC (very large crude carrier) tanker. This ship model is used by the Foundation for Safety of Navigation and Environment Protection for training captains on the Silm lake near Iława, Poland. The basic task for course participants is to test large tanker maneuvers in various navigation situations (Iława, 2016). The main parameters are shown in Table 1. This model is equipped with one rudder, one propeller screw, two tunnel thrusters (one at bow and one at stern), and two rotating thrusters (one
Table 1. Main parameters of the training ship Blue Lady for the load condition (Gierusz, 2001).

\begin{tabular}{|l||rc|}
\hline Length overall $\left(L_{O A}\right)$ & 13.78 & $(\mathrm{~m})$ \\
Length between perpendiculars $\left(L_{P P}\right)$ & 13.50 & $(\mathrm{~m})$ \\
Beam $(B)$ & 2.38 & $(\mathrm{~m})$ \\
Draft $(T)$ & 0.86 & $(\mathrm{~m})$ \\
Displacement $(\Delta)$ & 22.93 & $\left(\mathrm{~m}^{3}\right)$ \\
\hline
\end{tabular}

at bow and one at stern). The locations of all installed propellers are shown in Fig. 2. The control of these propellers makes use of a set of eight commands: rudder angle $\delta_{c}(\mathrm{deg})$, main propeller revolutions $n_{1 c}(\mathrm{rpm})$, relative propeller revolutions of the bow (stern) tunnel thruster $p_{2 c}\left(p_{3 c}\right)(-)$, turning angle of the movable bow (stern) thruster $\alpha_{4 c}\left(\alpha_{5 c}\right)$ (deg), and relative propeller revolutions of the movable bow (stern) thruster $p_{4 c}$ $\left(p_{5 c}\right)(-)$.

In the developed hybrid switching controller, only

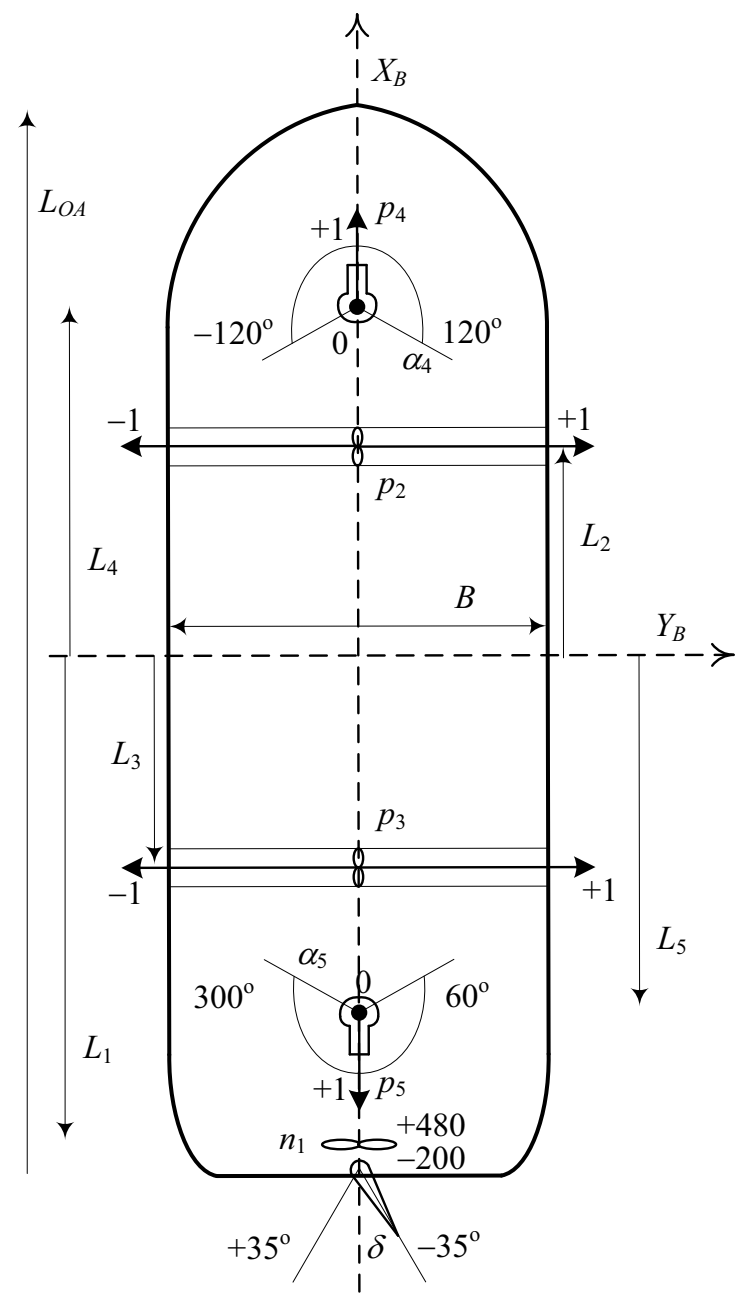

Fig. 2. Locations of thrusters on Blue Lady. 
four actuators are used, which are the rudder $(\delta)$, the main propeller $\left(n_{1}\right)$, and two tunnel thrusters: bow $\left(p_{2}\right)$ and stern $\left(p_{3}\right)$. The complex mathematical model of Blue Lady dynamics (including the modeled actuators) which well reflects real behavior of the training ship, was worked out by Gierusz (2001).

In a general form, the mathematical model of the ship of interest is given by the formula

$$
M \dot{\nu}+C(\nu) \nu+D(\nu) \nu=\tau,
$$

where $M$ represents the positive definite inertia mass matrix which includes the added mass, $\boldsymbol{C}(\boldsymbol{\nu})$ denotes the Coriolis centripetal matrix, $\boldsymbol{D}(\boldsymbol{\nu})$ is the damping matrix, and $\tau$ is the vector of forces and moment acting on the ship.

2.2. Kalman filter. The position coordinates $(x, y)$ are measured by the DGPS (differential global positioning system), while the ship heading $\psi$ is measured by the gyrocompass. These three state variables are collected in the vector $\boldsymbol{\eta}=[x, y, \psi]^{\mathrm{T}}$. The three remaining state variables, which are to be estimated, are collected in the vector $\boldsymbol{\nu}=[u, v, r]^{\mathrm{T}}$. The velocity vector $\boldsymbol{\nu}$ expressed in the body-fixed frame $\left(X_{B}, Y_{B}\right)$ can be calculated from velocities determined in the inertial Earth-fixed frame $\left(X_{N}, Y_{N}\right)$ using the relation

$$
\left[\begin{array}{c}
u \\
v \\
r
\end{array}\right]=\left[\begin{array}{ccc}
\cos (\psi) & \sin (\psi) & 0 \\
-\sin (\psi) & \cos (\psi) & 0 \\
0 & 0 & 1
\end{array}\right]\left[\begin{array}{c}
u_{x} \\
v_{x} \\
r
\end{array}\right],
$$

where $u_{x}=\mathrm{d} x / \mathrm{d} t, v_{y}=\mathrm{d} y / \mathrm{d} t, r=\mathrm{d} \psi / \mathrm{d} t$ are the velocities in the inertial frame.

The components of the Earth-fixed velocity vector $\left(u_{x}, v_{y}, r\right)$ for the training ship Blue Lady were determined using the discrete-time Kalman filter, which was described in detail by Tomera (2010). Kalman filtering as a tool for state estimation is described more closely by Gelb (1974) or Brown and Hwang (2012), for instance.

\section{Supervisory switching control}

In the supervisory switching control system, two separate main blocks can be named, the supervisor and the bank of controllers. Supervisory switching control is used to control the movement of the ship in a number of operating modes. The block diagram of the integrated circuit is shown in Fig. 3. The system provides the control of the ship movement in typical operations related to navigating from one port to another. The developed hybrid controller allows controlling four different operations carried out by the ship. These operations are designated by control modes. The direct ship control system contains a set of five controllers, switched depending on the currently

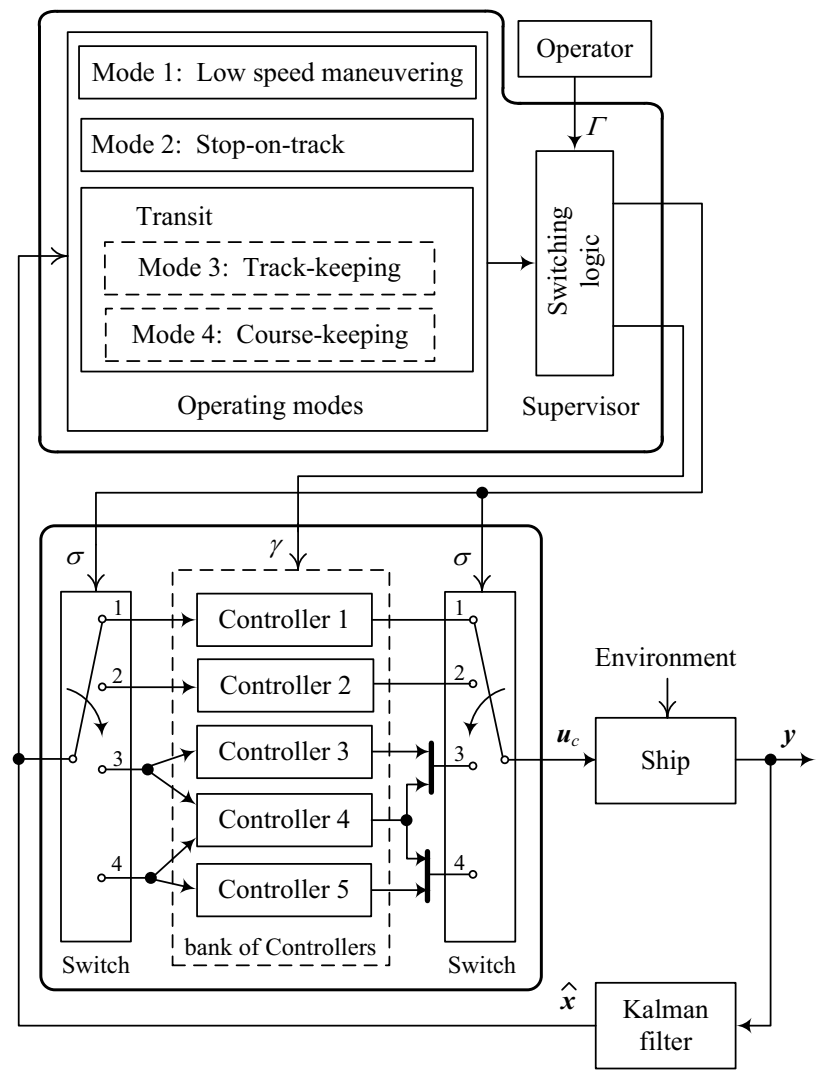

Fig. 3. Block diagram of the integrated hybrid switching controller, where $\Gamma$ is the reference trajectory, $\gamma$ stands for data for direct controllers, $\sigma$ is the switching signal, Controller 1 is the multivariable precision controller, Controller 2 is the multivariable low speed controller, Controller 3 is the track-keeping controller, Controller 4 is the surge speed controller, and Controller 5 is the coursekeeping controller.

conducted control mode. Switching between controllers collected in the bank is performed using the switching signal $\sigma$, whose value depends on the selected operating mode.

The supervisor operates based on the reference trajectory $\Gamma$ obtained from the system operator. In the future this trajectory is expected to be obtained from the master ship trajectory planning system. The trajectory contains coordinates of waypoints of the executed ship transit route, with certain operation modes assigned to each trajectory segment. When the ship has to move in low speed maneuvering mode (Mode 1) along a given trajectory segment, the ship course, which is not necessarily compatible with the direction of the ship motion, is also included. If the mode of operation is 'Transit' (Modes 3 or 4), the ship speed on the specified trajectory segment is additionally given. These two modes in the hybrid control system make use of ship surge speed 
control, denoted as Controller 4. The operations described by Modes 3 and 4 are commonly referred to as 'Transit' operations in the literature.

In the bank of switching controllers, only those which have received the "switch-on" signal are enabled. If the controller is off (not enabled), it is in the idle state and not working. In the enabled controllers the integrators are zeroed after each change in the reference trajectory segment. When the reference trajectory segment is changed, the supervisory system passes new set-points to the inputs of the enabled component controllers.

3.1. Reference trajectory. The simplest way of steering a ship is to define the trajectory in the form of segments joining successive points of the route (Fig. 4). Three coordinate systems have been defined to describe the reference trajectory and the ship motion along it. The first system is the coordinate one $\left(X_{N}, Y_{N}\right)$, fixed to the map of the basin (Earth-fixed reference frame). Here, the $X_{N}$ and $Y_{N}$ axes indicate the northern and eastern directions, respectively. Consecutive waypoints $\left(x_{k}, y_{k}\right)$ are defined in this coordinate system. The reference trajectory is a dashed line consisting of successive segments joining $N$ waypoints. For each waypoint, the

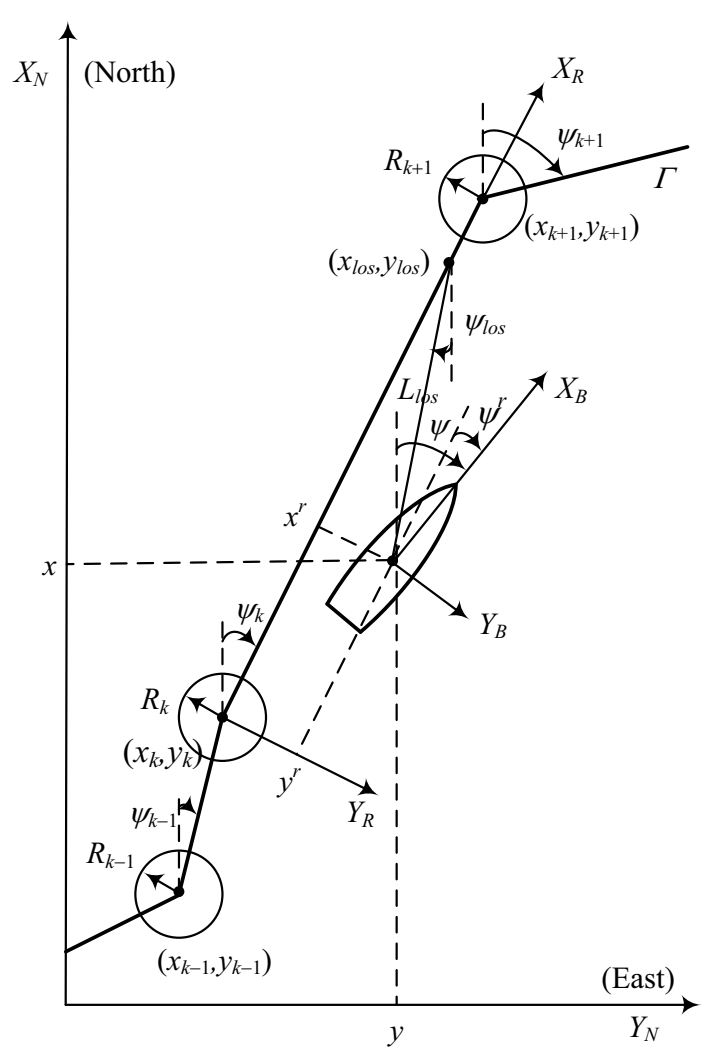

Fig. 4. Reference trajectory $\Gamma$ and three defined coordinate frames. vector $\boldsymbol{p}_{k}=\left[x_{k}, y_{k}, \psi_{k}\right]^{\mathrm{T}}$ is defined which contains the coordinates of the position $\left(x_{k}, y_{k}\right)$ and the course $\psi_{k}$ of the trajectory segment which ends at the next waypoint $\left(x_{k+1}, y_{k+1}\right)$. The course angle is the right-hand angle $\psi_{k}$ measured from the $X_{N}$ axis,

$$
\psi_{k}=\operatorname{atan} 2\left(y_{k+1}-y_{k}, x_{k+1}-x_{k}\right) .
$$

Around each waypoint, a circle with radius $R_{k}$ is defined. When the ship reaches this circle, the reference trajectory is switched to the next section of the route. The desired surge ship speed $u_{d k}$ and the desired ship course $\psi_{d k}$, which are not necessarily consistent with the direction of the executed trajectory segment, can be additionally associated with each stretch of the route.

The second path-fixed reference frame $\left(X_{R}, Y_{R}\right)$ is associated with the currently implemented segment of the reference trajectory, the end coordinates of which are $\left(x_{k}, y_{k}\right)$ and $\left(x_{k+1}, y_{k+1}\right)$. The origin of the reference system is the starting point of the trajectory segment $\left(x_{k}, y_{k}\right)$, and the $X_{R}$ axis coincides with the segment along which the ship sails. The ship position coordinates $\boldsymbol{\eta}^{r}=\left[x^{r}, y^{r}, \psi^{r}\right]^{\mathrm{T}}$ in the reference system $\left(X_{R}, Y_{R}\right)$ can be easily recalculated from the position coordinates $\boldsymbol{\eta}=[x, y, \psi]^{\mathrm{T}}$ measured in the reference frame $\left(X_{N}, Y_{N}\right)$ according to the formula

$$
\boldsymbol{\eta}^{r}=\boldsymbol{R}^{\mathrm{T}}\left(\psi_{k}\right)\left(\boldsymbol{\eta}-\boldsymbol{p}_{\boldsymbol{k}}\right),
$$

wherein $\psi_{k}$ is the angle defined with respect to the $X_{N}$ axis, for the trajectory segment fixed between waypoints $\boldsymbol{p}_{k}$ and $\boldsymbol{p}_{k+1}$, while $\boldsymbol{R}\left(\psi_{k}\right)$ is the rotation matrix given by the formula (2).

The third body-fixed reference frame $\left(X_{B}, Y_{B}\right)$ is fixed to the hull of the moving ship and used to express linear $(u, v)$ and angular $(r)$ velocities (Fig. 1). The origin of this system is on the water line, at the point corresponding to the ship's center of gravity.

3.2. Low speed maneuvering (Mode 1). This mode consists in maneuvering the ship at low speeds. It is used to steer the ship in the port, in canals, in access passages to the port, and during dock entering maneuvers. A multivariable precise controller, denoted as Controller 1, is associated with this mode. In this mode, ship steering is carried out using the main propeller $\left(n_{1}\right)$ and the tunnel thrusters: bow $\left(p_{2}\right)$ and stern $\left(p_{3}\right)$. At low speeds the use of the ship's rudder is not very effective. Ship control in this mode consists in moving the ship along trajectory segments connecting two consecutive waypoints, during which ship settings described by the course at the start and end points are additionally taken into account. Here, various ship movements, such as a longitudinal and/or a transverse movement, a movement at a certain angle, and ship rotation around its axis by a specified angle, are possible. 
3.3. Stop-on-track (Mode 2). The stop-on-track maneuver (Mode 2) is executed by the ship in accessing passages to a port or to narrow passages, and is related with switching both from the track-keeping (Mode 3) or from the course-keeping (Mode 4) to low-speed maneuvering (Mode 1). In this mode, ship stopping is done using the main propeller $\left(n_{1}\right)$ and the tunnel thrusters: bow $\left(p_{2}\right)$ and stern $\left(p_{3}\right)$. The stopping maneuver is performed on the stretch of the road known as the braking distance $L_{\text {stop }}$, whose length depends on the surge speed of the ship at the beginning of the maneuver. The relation between the braking distance $L_{\text {stop }}$ and the surge speed of the ship was determined in experimental research on a real plant. The measured values were used to determine curves approximating the measured points, based on the formula

$$
L_{\text {stop }}=a_{\text {stop }} u+b_{\text {stop }},
$$

where $u$ is the surge velocity of the ship, while $a_{\text {stop }}$ and $b_{\text {stop }}$ are the coefficients of the straight line approximating the measured ship braking distances. The ship is assumed to stop when the surge speed $u$ drops below a given level $u_{\text {stop }}\left(u<u_{\text {stop }}\right)$. Ship stopping on the trajectory allows the control system to switch from Modes 3 or 4 to 1 .

3.4. Track-keeping (Mode 3). This mode consists in controlling the ship movement at a desired speed along the reference trajectory, composed of segments joining successive waypoints. Two controllers: the track-keeping one (Controller 3) and the surge speed one (Controller 4) are associated with this mode. The task of the former is to determine the rudder deflection angle $(\delta)$ and to minimize the lateral deviation $\left(e_{y}\right)$ from the executed reference trajectory segment. The task of the latter is to control the revolutions of the main propulsion screw $\left(n_{1}\right)$ and maintain the desired surge speed $\left(u_{d}\right)$. The lateral deviation of the ship position from the reference trajectory $e_{y}$ is calculated using the following formula:

$$
e_{y}=\left(x-x_{k}\right) \sin \psi_{k}-\left(y-y_{k}\right) \cos \psi_{k},
$$

where $\left(x_{k}, y_{k}\right)$ are the coordinates of the starting point of the executed trajectory segment and $(x, y)$ are the coordinates of the current position of the ship.

Once the ship has passed the trajectory segment connecting points $\boldsymbol{p}_{k}$ and $\boldsymbol{p}_{k+1}$, a mechanism for automatically selecting the next segment of the route is needed. Point $\boldsymbol{p}_{k+1}$ has the coordinates $\left(x_{k+1}, y_{k+1}\right)$, and the circle of radius $R_{k+1}$ is defined around this point. If the ship position $(x, y)$ at time $t$ satisfies the condition

$$
\left(x_{k+1}-x\right)^{2}+\left(y_{k+1}-y\right)^{2} \leq R_{k+1}^{2},
$$

then this mechanism should switch the reference trajectory to the next section of the route connecting points $\boldsymbol{p}_{k+1}$ and $\boldsymbol{p}_{k+2}$. The length of the above radius is usually assumed to be equal to two ship lengths: $R_{k+1}=2 L_{O A}$.

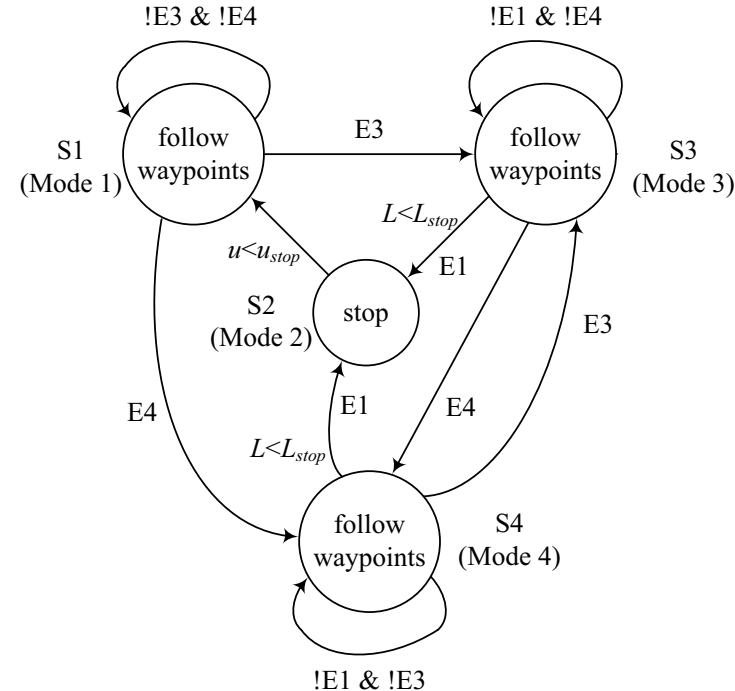

Fig. 5. Graph showing supervisory controller operation modes and possible switches between them, where Mode 1 is low speed maneuvering, Mode 2 is stop-on-track, Mode 3 is track-keeping, and Mode 4 is course-keeping.

3.5. Course-keeping (Mode 4). This mode consists in controlling the ship movement at a desired speed and course, and is typical for the ship steering on open waters with no natural constraints on the ship movement, such as very narrow passages or lands. Two direct controllers, the surge speed one (Controller 4) and the course-keeping one (Controller 5), are associated with this mode. The task of the latter is to calculate the commanded rudder angle $\left(\delta_{c}\right)$, while the former controls revolutions of the main propulsion screw $\left(n_{1 c}\right)$. The desired ship course $\psi_{\text {los }}$ for the course-keeping controller is calculated from

$$
\psi_{d}=\psi_{l o s}=\operatorname{atan} 2\left(y_{l o s}-y, x_{l o s}-x\right),
$$

where $\left(x_{l o s}, y_{l o s}\right)$ are the coordinates of the reference trajectory point situated at the distance $L_{l o s}$ in front of the moving ship and $(x, y)$ are the ship position coordinates (Fig. 4). The coordinates $\left(x_{l o s}, y_{l o s}\right)$ are moved along the reference trajectory segment until they reach the location of the next waypoint $\left(x_{k+1}, y_{k+1}\right)$. Then they are kept fixed at this point until the ship gets inside the radius $R_{k+1}$ (9). After switching to the next trajectory segment, the point $\left(x_{l o s}, y_{l o s}\right)$ starts again to move at the distance $L_{l o s}$ in front of the moving ship, until the next waypoint $\left(x_{k+2}\right.$, $\left.y_{k+2}\right)$ is reached. This principle has been adopted for the ship to sail directly at the next waypoint in the final phase of sailing along the reference trajectory segment.

3.6. Structure of the supervisory system. The structure of the supervisory system is shown in Fig. 5 as a directed graph in which the nodes represent operating modes of the hybrid controller. Each operating mode is 
associated with a discrete state of the supervisory system, labeled as S1, S2, S3, S4. The ship operation modes are associated with the discrete states of the supervisory controller in the following way: Mode 1 is S1, Mode 2 is S2, Mode 3 is S3, and Mode 4 is S4. The labeled arcs representing possible switches between the operating modes in the hybrid controller are denoted as E1, E3, E4.

Supervisory controller states are changed when the operation performed by the ship is changed, which involves switching between component controllers. Below are described possible switches between hybrid controller operation modes, which are the discrete states of the supervisory system.

- E1 means changing the operating mode to low speed maneuvering (Mode 1). This switching is possible when changing from both track-keeping control (Mode 3) and course-keeping control (Mode 4). This change of modes requires stopping the ship on the route (Mode 2). The stop-on-track maneuver is started in advance, at the distance $L_{\text {stop }}$ from another waypoint, from which the ship motion is going to be controlled in Mode 1. The maneuver of stopping the ship along the distance $L_{\text {stop }}$ is executed in Mode 2 . Then, switching from Mode 2 to Mode 1 is done automatically after reducing the ship surge speed $u$ below some limit $u_{\text {stop }}\left(u<u_{\text {stop }}\right)$.

- E3 means changing the operating mode to track-keeping control (Mode 3). Such switching is possible from both low speed maneuvering (Mode 1) and course-keeping control (Mode 4).

- E4 means changing the operating mode to course-keeping control (Mode 4). Such switching is possible from both low speed maneuvering (Mode 1) and track-keeping control (Mode 3).

The operation of the supervisory controller can be initialized from Modes 1, 3, or 4.

\section{Switching controller design}

The component controllers allow executing the operating modes of the ship motion described in Section 3. In the direct control system, all switching controllers use a Kalman filter to determine the unmeasured linear $(u, v)$ and angular $r$ velocities of the ship motion and to filter the measurement noise in the measured ship position coordinates $(x, y)$ and the ship heading $\psi$.

4.1. Multivariable precision controller (Controller 1). This controller has been described in detail by Tomera (2014). It is designed to control the movement of the ship at low speeds and is based on a simplified mathematical model of the ship, obtained from Eqn. (3), described using the following formula (Fossen, 2011):

$$
M \dot{\nu}+D_{L} \nu=\tau
$$

The matrix $M$ contains inertia parameters of the rigid body, its dimensions, weight, weight distribution, volume, etc., and the added mass coefficients,

$$
\boldsymbol{M}=\left[\begin{array}{ccc}
m-X_{\dot{u}} & 0 & 0 \\
0 & m-Y_{\dot{v}} & m x_{G}-Y_{\dot{r}} \\
0 & m x_{G}-N_{\dot{v}} & I_{z}-N_{\dot{r}}
\end{array}\right]
$$

The linear damping matrix $\boldsymbol{D}_{L}$ relates to hydrodynamic damping forces and is determined for a small and constant surge speed $\boldsymbol{\nu}=\boldsymbol{\nu}_{0}=\left[u_{0}, 0,0\right]^{\mathrm{T}}($ Fossen, 2011),

$$
\boldsymbol{D}_{L}=\left[\begin{array}{ccc}
-X_{u} & 0 & 0 \\
0 & -Y_{v} & -Y_{r} \\
0 & -N_{v} & -N_{r}
\end{array}\right]
$$

For the multivariable precision controller, the aim of control is to track the desired smooth trajectory $\left(\boldsymbol{\eta}_{d}^{r}(t)\right.$, $\left.\dot{\boldsymbol{\eta}}_{d}^{r}(t), \ddot{\boldsymbol{\eta}}_{d}^{r}(t)\right)$ defined by the ship guidance system in the path-fixed reference frame $\left(X_{R}, Y_{R}\right)$. The coordinates of the destination point to which the ship moves along a given trajectory segment are calculated in the reference frame $\left(X_{R}, Y_{R}\right)$ using the following formula:

$$
\boldsymbol{\eta}_{K}^{r}=\boldsymbol{R}^{\mathrm{T}}\left(\psi_{P}\right)\left(\boldsymbol{\eta}_{K}-\boldsymbol{\eta}_{\boldsymbol{P}}\right),
$$

where $\boldsymbol{\eta}_{P}=\left[x_{P}, y_{P}, \psi_{P}\right]^{\mathrm{T}}$ and $\boldsymbol{\eta}_{K}=\left[x_{K}, y_{K}, \psi_{K}\right]^{\mathrm{T}}$ are the desired ship position vectors at the initial point $(P)$ and the final point $(K)$, expressed in the Earth-fixed reference frame $\left(X_{N}, Y_{N}\right), \boldsymbol{R}$ is the rotation matrix given by the formula (2), and $\psi_{P}$ is the desired ship course at the initial point of the trajectory segment.

The desired coordinates of the position $\boldsymbol{\eta}_{d}^{r}(t)$, the speeds of movement $\dot{\boldsymbol{\eta}}_{d}^{r}(t)$, and the acceleration $\ddot{\boldsymbol{\eta}}_{d}^{r}(t)$ of the ship moving from the initial point $(P)$ to the final point $(K)$ are calculated in the reference system shown in Fig. 6. The reference model was chosen as a second-order one with diagonal design matrices of relative damping ratios $\boldsymbol{Z}=\operatorname{diag}\left\{\zeta_{1}, \zeta_{2}, \zeta_{3}\right\}$ and natural frequencies $\boldsymbol{\Omega}_{n}=$ $\operatorname{diag}\left\{\omega_{n 1}, \omega_{n 2}, \omega_{n 3}\right\}$ and $\boldsymbol{\eta}_{K}^{r}$ as the commanded input vector. The desired values of speeds $\dot{\boldsymbol{\eta}}_{d}^{r}$ and accelerations $\ddot{\boldsymbol{\eta}}_{d}^{r}$ along the route should not exceed physical limits for the ship, which is why the configuration shown in Fig. 6 includes appropriate signal limits.

The control system calculates deviations from the desired values. The position error $\boldsymbol{\eta}_{e}^{r}$ is calculated in the path-fixed reference frame $\left(X_{R}, Y_{R}\right)$ associated with the executed reference trajectory segment, while the deviations in the velocity $\nu_{e}$ and the acceleration $\dot{\nu}_{e}$ are calculated in the body-fixed frame $\left(X_{B}, Y_{B}\right)$ attached to the moving ship,

$$
\boldsymbol{\eta}_{e}^{r}=\boldsymbol{\eta}^{r}-\boldsymbol{\eta}_{d}^{r}
$$




$$
\begin{aligned}
& \boldsymbol{\nu}_{e}=\boldsymbol{\nu}-\boldsymbol{\nu}_{d} \\
& \dot{\boldsymbol{\nu}}_{e}=\dot{\boldsymbol{\nu}}-\dot{\boldsymbol{\nu}}_{d} .
\end{aligned}
$$

The position vector $\boldsymbol{\eta}=[x, y, \psi]^{\mathrm{T}}$ of the ship, which is measured in the Earth-fixed reference frame $\left(X_{N}, Y_{N}\right)$, is transformed to the path-fixed frame $\left(X_{R}, Y_{R}\right)$ in the following way:

$$
\boldsymbol{\eta}^{r}=\boldsymbol{R}^{\mathrm{T}}\left(\psi_{P}\right)\left(\boldsymbol{\eta}-\boldsymbol{\eta}_{\boldsymbol{P}}\right)
$$

while the desired velocities $\dot{\boldsymbol{\eta}}_{d}^{r}$ and accelerations $\ddot{\boldsymbol{\eta}}_{d}^{r}$ are calculated to the body-fixed reference frame $\left(X_{B}, Y_{B}\right)$ as follows:

$$
\begin{gathered}
\boldsymbol{\nu}_{d}=\boldsymbol{R}^{\mathrm{T}}\left(\psi_{e}^{r}\right) \dot{\boldsymbol{\eta}}_{d}^{r} \\
\dot{\boldsymbol{\nu}}_{d}=\dot{\psi}_{e}^{r} \boldsymbol{S}^{\mathrm{T}} \boldsymbol{R}^{\mathrm{T}}\left(\psi_{e}^{r}\right) \dot{\boldsymbol{\eta}}_{d}^{r}+\boldsymbol{R}^{\mathrm{T}}\left(\psi_{e}^{r}\right) \ddot{\boldsymbol{\eta}}_{d}^{r} .
\end{gathered}
$$

Here $\boldsymbol{R}$ is the rotation matrix determined from Eqn. (2) and the matrix $S$ has the following form:

$$
\boldsymbol{S}=\left[\begin{array}{rrr}
0 & -1 & 0 \\
1 & 0 & 0 \\
0 & 0 & 0
\end{array}\right]
$$

The deviations from the desired values are minimized by the control system having the form

$$
\dot{\boldsymbol{\nu}}_{e}+\boldsymbol{K}_{P} \boldsymbol{\eta}_{e}^{r}+\boldsymbol{K}_{I} \boldsymbol{\xi}_{e}^{r}+\boldsymbol{K}_{D} \boldsymbol{\nu}_{e}=0
$$

where

$$
\dot{\boldsymbol{\xi}}_{e}^{r}=\boldsymbol{\eta}_{e}^{r} .
$$

The multivariable precision controller was designed using the state feedback linearization method. The final form of the control algorithm of the multivariable precision controller is

$$
\begin{aligned}
\boldsymbol{\tau}_{c}= & \boldsymbol{M} \boldsymbol{R}^{-1}\left(\psi^{r}\right)\left[\dot{\boldsymbol{\nu}}_{d}-\boldsymbol{K}_{P} \boldsymbol{\eta}_{e}^{r}-\boldsymbol{K}_{I} \boldsymbol{\xi}_{e}^{r}-\boldsymbol{K}_{D} \boldsymbol{\nu}_{e}\right. \\
& \left.-r \boldsymbol{M} \boldsymbol{R}\left(\psi^{r}\right) \boldsymbol{S} \boldsymbol{\nu}\right]+\boldsymbol{D}_{L} \boldsymbol{\nu}
\end{aligned}
$$

The predetermined vector of moments acting on the ship hull is composed of three components $\boldsymbol{\tau}_{c}=\left[\tau_{c X}, \tau_{c Y}, \tau_{c N}\right]^{\mathrm{T}}$, which need to be generated by the thrusters installed on the ship. In this case, the control is carried out in three degrees of freedom using three thrusters; therefore, there is no need to develop an

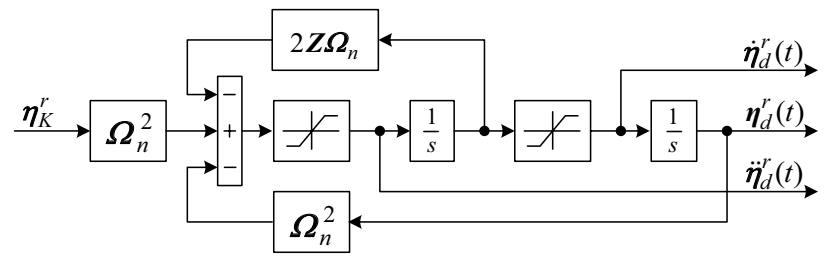

Fig. 6. Reference model which generates desired signals for the multivariable precision controller. additional allocation algorithm for the thrusters, and it is sufficient only to invert the matrix of thruster locations,

$$
\left[\begin{array}{c}
F_{1 c}\left(n_{1 c}\right) \\
F_{2 c}\left(p_{2 c}\right) \\
F_{3 c}\left(p_{3 c}\right)
\end{array}\right]=\left[\begin{array}{ccc}
1 & 0 & 0 \\
0 & 1 & 1 \\
0 & L_{2} & -L_{3}
\end{array}\right]^{-1}\left[\begin{array}{c}
\tau_{c X} \\
\tau_{c Y} \\
\tau_{c N}
\end{array}\right],
$$

where $L_{2}$ and $L_{3}$ are the distances of the tunnel thrusters from the geometric center of the ship.

After allocating relevant forces to particular propellers, the commanded inputs for the main propeller $\left(n_{1 c}\right)$ and tunnel thrusters $\left(p_{2 c}, p_{3 c}\right)$ are as follows:

$$
\begin{gathered}
n_{1 c}=\operatorname{sgn}\left(F_{1 c}\right) \sqrt{\frac{F_{1 c}}{X_{n}}} \\
p_{i c}=\frac{F_{i c}}{Y_{p}}, \quad i \in\{2,3\},
\end{gathered}
$$

where $X_{n}$ and $Y_{p}$ are the determined coefficients of linearized forces generated by the main propeller $\left(F_{1}\right)$ and tunnel thrusters: bow $\left(F_{2}\right)$ and stern $\left(F_{3}\right)$.

4.2. Multivariable low speed controller (Controller 2). This controller is used in the hybrid controller to stop the ship at the set trajectory. Its task is to control the ship motion at low speeds, when the operation of the rudder $(\delta)$ is not efficient. The design of a multivariable low speed controller is based on the mathematical model of the ship described by Eqn. (3), in which the matrix $M$ is expressed by the formula (12). The Coriolis-centripetal matrix $C$, which includes hydrodynamic Coriolis and centripetal terms connected with the fluid in which the ship moves, has the form (Fossen, 2011)

$$
\boldsymbol{C}(\boldsymbol{\nu})=\left[\begin{array}{ccc}
0 & 0 & c_{13} \\
0 & 0 & \left(m-X_{\dot{u}}\right) u \\
-c_{13} & -\left(m-X_{\dot{u}}\right) u & 0
\end{array}\right]
$$

where $c_{13}=-m\left(x_{G} r+v\right)+Y_{\dot{v}} v+Y_{\dot{r}} r$. The damping matrix $\boldsymbol{D}(\boldsymbol{\nu})$, which relates to hydrodynamic damping forces and makes it possible to determine these forces at high speeds, has the form (Fossen, 2011)

$$
\boldsymbol{D}(\boldsymbol{\nu})=\left[\begin{array}{ccc}
-d_{11}(\boldsymbol{\nu}) & 0 & 0 \\
0 & -d_{22}(\boldsymbol{\nu}) & -d_{23}(\boldsymbol{\nu}) \\
0 & -d_{32}(\boldsymbol{\nu}) & -d_{33}(\boldsymbol{\nu})
\end{array}\right]
$$

where $d_{11}=X_{|u| u}|u|, d_{22}=Y_{|u| v}|u|+Y_{|v| v}|v|+Y_{|r| v}|r|$, $d_{23}=Y_{|u| r}|u|+Y_{|v| r}|v|+Y_{|r| r}|r|, d_{32}=N_{|u| v}|u|+$ $N_{|v| v}|v|+N_{|r| v|r|}, d_{33}=N_{|u| r \mid}|u|+N_{|v| r}|v|+N_{|r| r \mid}|r|$.

The task of Controller 2 is to track the desired smooth trajectory $\left(\boldsymbol{\nu}_{d}(t), \dot{\boldsymbol{\nu}}_{d}(t)\right)$ determined by the reference model whose block diagram is shown in Fig. 7. The reference model is simply chosen as a first-order one with time constants $\boldsymbol{T}=\operatorname{diag}\left\{T_{1}, T_{2}, T_{3}\right\}$ and $\boldsymbol{r}_{\nu}=$ 


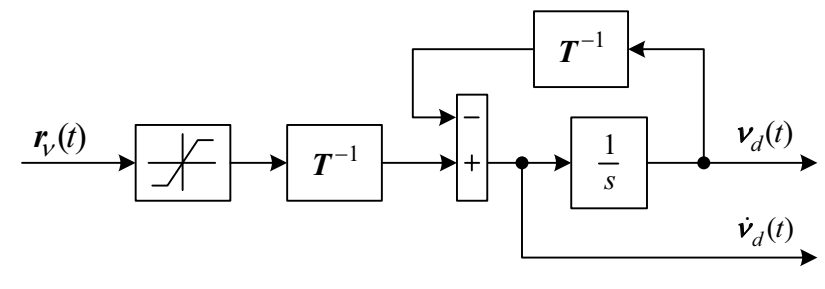

Fig. 7. Reference model which generates desired commands for the multivariable low speed controller.

$\left[u_{d}, v_{d}, r_{d}\right]^{\mathrm{T}}$ as the commanded input vector. The control system calculates the deviations from the desired values,

$$
\begin{aligned}
& \boldsymbol{\nu}_{e}=\boldsymbol{\nu}-\boldsymbol{\nu}_{d}, \\
& \dot{\boldsymbol{\nu}}_{e}=\dot{\boldsymbol{\nu}}-\dot{\boldsymbol{\nu}}_{d} .
\end{aligned}
$$

These deviations are minimized using the algorithm in the form

$$
\dot{\nu}_{e}+\boldsymbol{K}_{P} \boldsymbol{\nu}_{e}+\boldsymbol{K}_{I} \boldsymbol{\xi}_{e}=0
$$

where

$$
\dot{\boldsymbol{\xi}}_{e}=\boldsymbol{\nu}_{e}
$$

The multivariable low speed controller was designed using the state feedback linearization method, and the final formula describing the operating algorithm has the form

$$
\begin{aligned}
\boldsymbol{\tau}_{c}= & \boldsymbol{M}\left[\dot{\boldsymbol{\nu}}_{d}-\boldsymbol{K}_{P} \boldsymbol{\nu}_{e}-\boldsymbol{K}_{I} \boldsymbol{\xi}_{e}\right] \\
& +\boldsymbol{C}(\boldsymbol{\nu}) \boldsymbol{\nu}+\boldsymbol{D}(\boldsymbol{\nu}) \boldsymbol{\nu}
\end{aligned}
$$

The resultant vector of desired forces and moment $\tau_{c}$ is distributed into the thrusters applied: the propeller and the tunnel one in the same way as for the multivariable precision controller, see Section 4.1.

4.3. Track-keeping controller (Controller 3). The ship motion along the desired route is controlled using the state controller designed on the basis of the linearized mathematical model of the process. For purposes of track-keeping controller design, the ship dynamics represented by the formula (3) were simplified by assuming a constant surge speed of the ship, $u=u_{0} \approx$ constant, while the speeds $v$ and $r$ were assumed to take small values. Surge dynamics were separated from the above model, under the assumption of port/starboard symmetry. The surge force was linearized to the form $\tau_{X}=X_{n} n_{1}$. The forces acting on the ship hull depend linearly, as a rule, on the rudder angle $\delta$ according to the relations $\tau_{Y}=-Y_{\delta} \delta$ and $\tau_{N}=-N_{\delta} \delta$,

$$
\begin{aligned}
\left(m-X_{\dot{u}}\right) \dot{u}-X_{u} u & -\left(m-Y_{\dot{v}}\right) v r \\
& -\left(m x_{G}-Y_{\dot{r}}\right) r^{2}=X_{n} n_{1},
\end{aligned}
$$

and the yaw-sway dynamics, obtained from linearization of the equations of motion (3). This allows obtaining the model of Davidson and Schiff (1946),

$$
\boldsymbol{M}_{1} \dot{\boldsymbol{\nu}}_{1}+\boldsymbol{N}\left(u_{0}\right) \boldsymbol{\nu}_{1}=\boldsymbol{B} \delta
$$

where $\boldsymbol{\nu}_{1}=[v, r]^{\mathrm{T}}$ is the state vector, $\delta$ is the rudder angle, and the matrices $\boldsymbol{M}_{1}, \boldsymbol{N}\left(u_{0}\right)$ and $\boldsymbol{B}$ in Eqn. (36) are defined as (Fossen, 2011)

$$
\begin{gathered}
\boldsymbol{M}_{1}=\left[\begin{array}{cc}
m-Y_{\dot{v}} & m x_{G}-Y_{\dot{r}} \\
m x_{G}-N_{\dot{v}} & I_{z}-N_{\dot{r}}
\end{array}\right], \\
\boldsymbol{N}\left(u_{0}\right)=\boldsymbol{C}_{1}\left(u_{0}\right)+\boldsymbol{D}_{1 L}, \\
\boldsymbol{C}_{1}\left(u_{0}\right)=\left[\begin{array}{cc}
0 & \left(m-X_{\dot{u}}\right) u_{0} \\
\left(X_{\dot{u}}-Y_{\dot{v}}\right) u_{0} & \left(m x_{G}-Y_{\dot{r}}\right) u_{0}
\end{array}\right], \\
\boldsymbol{D}_{1 L}=\left[\begin{array}{cc}
-Y_{v} & -Y_{r} \\
-N_{v} & -N_{r}
\end{array}\right], \\
\boldsymbol{B}=\left[\begin{array}{c}
-Y_{\delta} \\
-N_{\delta}
\end{array}\right] .
\end{gathered}
$$

The track-keeping controller was designed using the method described by Holzhüter (1990) and has the form

$$
\delta_{c}=-k_{1} v-k_{2} r-k_{3} \psi^{r}-k_{4} y^{r}-k_{5} y_{I}^{r},
$$

where $\psi^{r}=\psi-\psi_{k}$. Here $\psi$ is the ship heading and $\psi_{k}$ is the course resulting from the execution of the current trajectory segment. Furthermore, $y_{I}^{r}$ is the integral of lateral deviation from the ship's reference route $y^{r}$, designated as follows:

$$
\dot{y}_{I}^{r}=y^{r}
$$

4.4. Surge speed controller (Controller 4). The training ship Blue Lady is equipped with a single propeller with varying rotational speed. Characteristics describing the relation between the rotational speed of the propeller $n_{1}$ and the steady-state surge speed $u$ of the ship in a straight trajectory segment $(v \approx 0)$ were determined using the path-keeping controller described in Section 4.3. In the experiment the rotational speed of the propeller $n_{1 c}$ was set manually, while the steering along the trajectory was done automatically using the path-keeping controller. These experiments were carried out on the lake in the presence of a wind, which changed its force and direction. The measured values were approximated using the least-squares method, having the following analytical form:

$$
n_{1}(u)=a_{n} u+b_{n} .
$$

The calculated approximation (44) is correct for the positive surge velocity and the ship movement along the linear reference route segment.

The surge speed controller design does not contain any filter for the reference signal; the only introduced 
constraint says that the desired surge speed of the ship movement is not higher than the maximum $u_{d}<u_{\text {max }}$. For this purpose the PI controller was applied in the following form (Breivik et al., 2008):

$$
n_{1 c}=n_{1}\left(u_{d}\right)+K_{P u} e_{u}+K_{I u} \int_{0}^{t} e_{u}(\tau) \mathrm{d} \tau,
$$

where $u_{d}$ is the desired surge speed and $e_{u}$ is the speed error $\left(e_{u}=u_{d}-u\right), K_{P u}>K_{I u}>0$.

4.5. Course-keeping controller (Controller 5). The ship motion on the course is controlled using a linear PID controller described by

$$
\delta_{c}=K_{P} e_{\psi}+K_{I} \int_{0}^{t} e_{\psi}(\tau) \mathrm{d} \tau+K_{D} r_{\psi}
$$

where $\delta_{c}$ is the commanded rudder angle, $e_{\psi}$ is the course error $\left(e_{\psi}=\psi_{d}-\psi\right), \psi_{d}$ is the desired course (10), $\psi$ is the measured course of the ship, and $r_{\psi}$ is the course error derivative $\left(r_{\psi}=\dot{e}_{\psi}\right)$.

The course-keeping controller (46) was designed based on the first Nomoto model (Nomoto et al., 1957) obtained from the linearized model of ship dynamics proposed by Davidson and Schiff (1946) and given by the formula (36), following removing the sway speed $v$ from these equations and further simplification, after which the first Nomoto model takes the form

$$
\frac{r(s)}{\delta(s)}=\frac{K}{s T+1} .
$$

Here $K$ is the static yaw rate gain and $T$ is the effective yaw rate time constant. Since the yaw rate is actually the time derivative of the ship heading angle $\dot{\psi}=r$, the model can be written in the time domain as

$$
T \ddot{\psi}+\dot{\psi}=K \delta
$$

The parameters of the linear PID controller were selected using the pole placement method and the Nomoto model of the ship (48), described in detail by Fossen (2011).

\section{Experimental results}

In order to check the correctness of the operation of the system shown in Fig. 3, both simulation studies and experimental research were conducted. The experimental studies were carried out on the training ship Blue Lady at the Ship Handling Research and Training Center on the lake Silm in Iława/Kamionka, Poland (Iława, 2016). The entire control system shown in Fig. 3 was modeled in the computing environment Matlab/Simulink. The supervisory controller, the switchable direct controller set, the discrete Kalman filter, and the allocation system of thrusters, as well as the complex mathematical model of Blue Lady dynamics, were written in the form of $\mathrm{S}$-functions in the Matlab code. The simulation studies carried out in this system consisted in maneuvering the ship along different reference trajectories and using different sequences of switching of particular components of the hybrid controller. The next step was translation of all S-functions from Matlab to $\mathrm{C}$ and their compilation to $\mathrm{C}-\mathrm{MEX}$ files, to enable activating the designed hybrid control system on real plants.

After conducting the simulation tests and making sure that the designed hybrid control system works properly, the next step was to verify these results on a real object. For this purpose, the control and measurement system worked out at the Department of Ship Automation in Gdynia Maritime University was used (Pomirski et al., 2012).

To assess the quality of the operation of the designed hybrid control system, a sample ship route recorded on the real plant is shown in Fig. 8. The lake Silm, where the operation of the hybrid switching controller was tested using the physical model of the ship Blue Lady, is prepared to train captains, and that is why it is equipped with various types of very narrow passages and quays. In particular, a large number of these structures is located in the bay shown in the bottom left corner of Fig. 8. The analyzed ship route consists of 10 waypoints. The beginning of the registered transit route is placed in the top right corner from which the ship sails out. After crossing the lake, the ship reaches the quay Mike (waypoint 10), situated in the port. In order to guide the ship along the route shown in Fig. 8, a sequence of switching modes given in Table 2 was executed by the supervisory controller.

Below are described in detail the operations performed by the ship in order to sail along the trajectory shown in Fig. 8 and listed in Table 2.

Mode 4 (S4). First, the ship sails through the area with no navigation obstacles. Hence, the supervisory controller is switched to Mode 4, associated with the surge speed controller (Controller 4) and the course-keeping one (Controller 5), cooperating with each other. The purpose of the latter controller is to control the ship's rudder angle $(\delta)$, while the former one controls the rotational speed of the main propeller $\left(n_{1}\right)$. The desired course $\left(\psi_{d}\right)$ for the course-keeping controller is determined by the

Table 2. Sequence of modes executed by the supervisory controller (Fig. 5) on the route in Fig. 8.

\begin{tabular}{|l||c|}
\hline \multicolumn{1}{|c||}{ Mode } & Range of waypoints \\
\hline Course-keeping (no. 4) & $1-2$ \\
Track-keeping (no. 3) & $2-6$ \\
Stop-on-track (no. 2) & 6 \\
Low speed maneuvering (no. 1) & $6-10$ \\
\hline
\end{tabular}




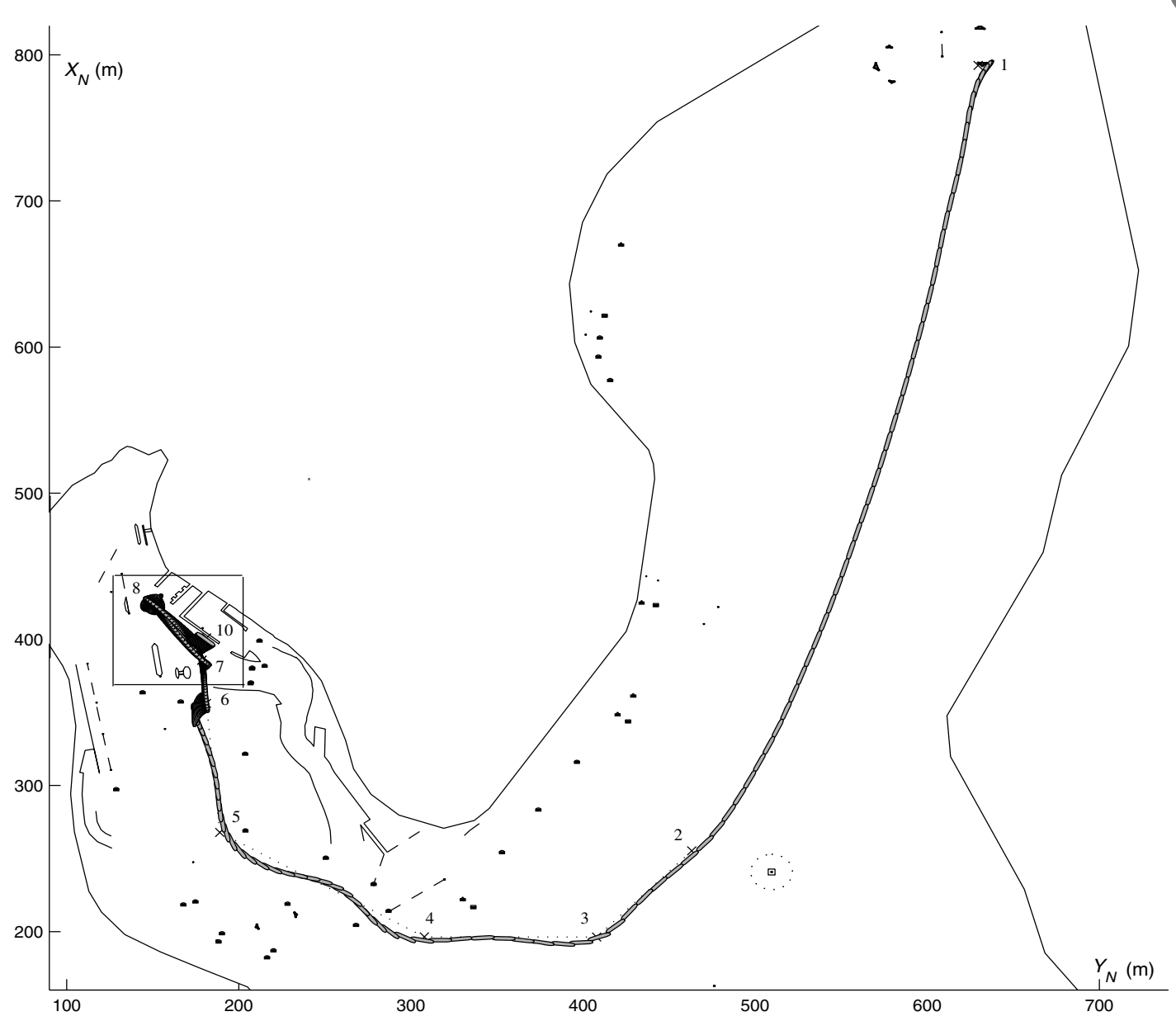

Fig. 8. Ship trajectory experimentally recorded on the lake Silm in Iława/Kamionka, Poland.

line-of-sight (LOS) rule given by the formula (10). The desired surge speed of the ship motion is $u_{d}=0.8(\mathrm{~m} / \mathrm{s})$.

Mode 3 (S3). After reaching the waypoint 2, the supervisory controller changes the operating mode to Mode 3, associated with the track-keeping one (Controller 3) and the surge speed controller (Controller 4), cooperating with each other. The ship enters the area with constraints in the form of very narrow passages, therefore it is important to accurately steer the ship along the trajectory, taking into account these constraints. This mode (Mode 3 ) is active along part of the reference trajectory between the waypoints 2 and 6. The desired surge speed for the trajectory segments between the waypoints 2 and 4 is $u_{d}=0.8(\mathrm{~m} / \mathrm{s})$, while for the segments between waypoints 4 to 6 it is reduced to $u_{d}=0.5(\mathrm{~m} / \mathrm{s})$. This surge speed decrease results from the fact that the ship is being prepared to perform the maneuver of entry to the port.

Mode 2 (S2). At a distance corresponding to the breaking distance $L_{\text {stop }}$ before the waypoint 6 the supervisory controller switches to Mode 2. The precise length of the distance at which this switching takes place depends on the surge speed of the moving ship and is calculated from the formula (7). Switching to the next mode occurs when the surge speed drops below a certain limit $u<u_{\text {stop }}$ $\left(u_{\text {stop }}=0.01(\mathrm{~m} / \mathrm{s})\right)$.

Mode 1 (S1). Mode 1 is related to the multivariable precision controller (Controller 1). Stopping the ship does not occur exactly at the target waypoint 6 in this case, but at a short distance from it. Therefore, the ship is first moved to the waypoint 6 and positioned at the desired position $\left(\boldsymbol{\eta}_{d}=\left[x_{d}, y_{d}, \psi_{d}\right]^{\mathrm{T}}\right)$.

In this operating mode ( $\mathrm{S} 1)$, the ship is moved from the waypoint 6 to the waypoint 10 (Fig. 9). Having reached the point 8 the ship is stopped, and then rotated by $180^{\circ}$ to reach the angle specified by the reference trajectory segment between the points 8 and 9 . After reaching the point 9 it executes the movement to the port side and stops at the quay Mike (waypoint 10).

Figures 10 and 11 show experimental time-histories recorded during the test trial of the training ship Blue Lady shown in Fig. 8. In all these figures, the time-histories 


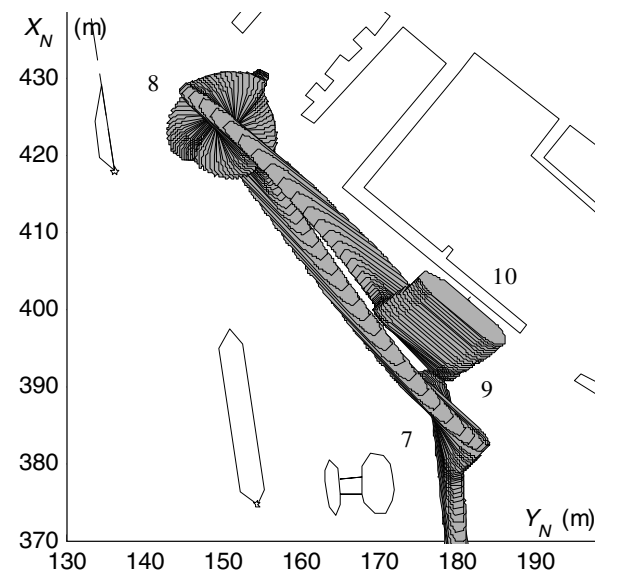

Fig. 9. Zoomed final section of the trajectory from Fig. 8.

denoted as (a) refer to changes in the operation modes of the supervisory controller. Figures 10(b)-(e) show the time-histories of the outputs of the hybrid switching controller which were passed to the actuators on the ship as commanded inputs signals. This figure shows that the main propulsion screw works in all modes, while the rudder is switched interchangeably with the bow and stern tunnel thrusters. The curves presented in this figure show that the commanded signals vary smoothly when switching between component controllers.

Solid lines in Figs. 11(b)-(e) represent the estimated speeds of the ship movement: surge $u$, sway $v$ and yaw $r$, and the measured relative wind speed $V_{w}$. The surge speed $u$ of the ship was controlled in each mode of supervisory controller operation, while two other speeds: sway $v$ and yaw $r$ only in Modes 1 and 2. The data shown in Fig. 11 reveal large fluctuations of sway speed $v$ and yaw speed $r$ in Mode 3. At that time the track-keeping controller minimized two control deviations, which were the ship course error $\psi_{e}$ and the lateral deviation from the executed section of the reference trajectory $e_{y}=y^{r}$.

\section{Conclusions}

The developed hybrid control system fulfills well its task, which consists in steering a ship sailing along the set passage route, from the starting point to the end point, and performing various operations on its way. For this purpose, the hybrid controller makes use of a number of switching component controllers and the information stored in the reference trajectory. In the present version, the trajectory is introduced by the system operator and contains coordinates of waypoints, surge velocity $u_{d}$, and operating modes $(\mathrm{S})$ attributed to particular segments between successive waypoints.

Conventional PID controllers were used in a bank of switching controllers. The research program also included examining the effect of replacement of those controllers by nonlinear units, based on the theory of sliding mode control (SMC) and fuzzy logic (FL), as well as by radial neural networks (RBFs). Unfortunately, in our opinion their application did not bring about a satisfactory improvement in the control quality of the developed hybrid controller, and therefore they were not discussed here.

The obtained results reveal that good quality control was obtained in Mode 1, when the ship made use of the multivariable precision controller. On the other hand, relatively poor quality control was observed in Mode 3, when the control covered a fairly wide range of surge speeds and its task was to minimize the lateral deviation from the required trajectory. This task was performed by Controller 3, which is a linear controller designed based on the linearized mathematical model of ship dynamics at speed $u_{0}=0.5(\mathrm{~m} / \mathrm{s})$. When the ship sailed along the predetermined trajectory section, side deviation oscillations were observed, which made maintaining the set surge speed by the ship more difficult. This deterioration in control quality along a given trajectory segment was more clearly visible when changing the ship speed to lower values.

\section{References}

Antsaklis, P.J. and Nerode, A. (1989). Hybrid control systems: An introductory discussion to the special issue, IEEE Transactions on Automatic Control 43(4): 457-460, DOI: 10.1109/TAC.1998.664148.

Balbis, L., Ordys, A., Grimble, M. and Pang, Y. (2007). Tutorial introduction to the modelling and control of hybrid systems, International Journal of Modelling, Identification and Control 2(4): 259-272, DOI: 10.1504/IJMIC.2007.016409.

Bańka, S., Brasel, M., Dworak, P. and Jaroszewski, K. (2015). A comparative and experimental study on gradient and genetic optimization algorithms for parameter identification of linear MIMO models of a drilling vessel, International Journal of Applied Mathematics and Computer Science 25(4): 877-893, DOI: 10.1515/amcs-2015-0063.

Breivik, M., Hovstein, V.E. and Fossen, T.I. (2008). Straight-line target tracking for unmanned surface vehicles, Modeling, Identification and Control 29(4): 131-149, DOI: $10.4173 / \mathrm{mic} .2008 .4 .2$.

Brodtkorb, A.H., Sorensen A.J. and Teel, A.R. (2014). Increasing the operation window of dynamic positioned vessels using the concept of hybrid control, Proceedings of the 33rd International Conference on Ocean, Offshore and Arctic Engineering, San Francisco, CA, USA.

Brown, R.G. and Hwang, P.Y.C. (2012). Introduction to Random Signals and Applied Kalman Filtering with Matlab Exercises, John Wiley \& Sons, New York, NY. 
a)

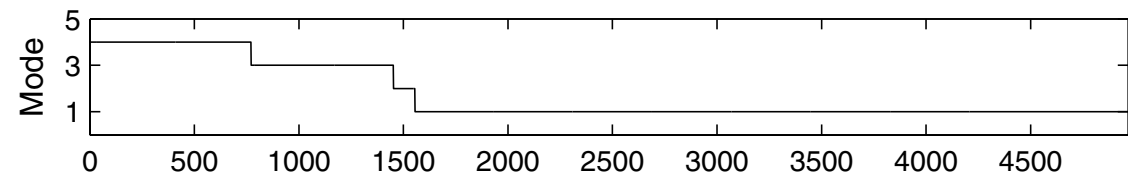

b)

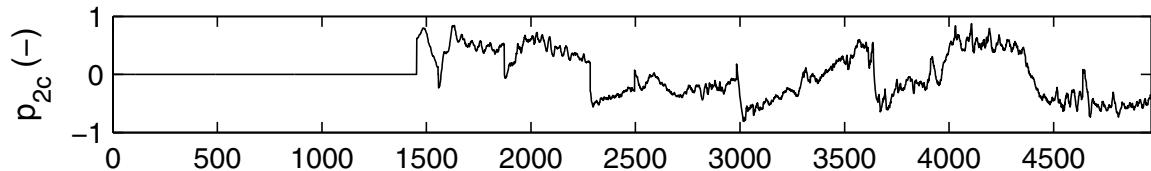

c)

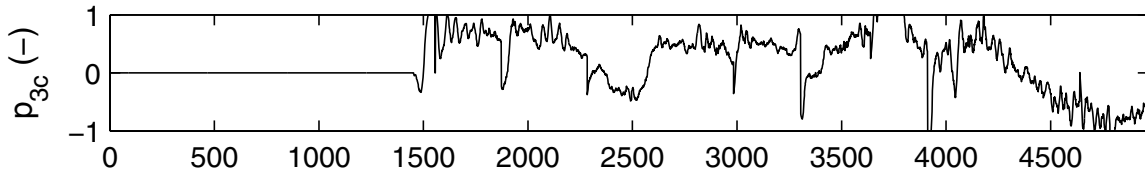

d)

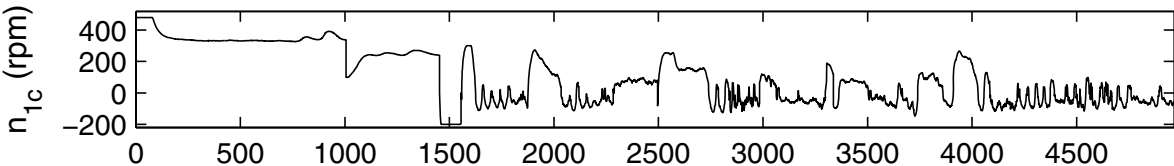

e)

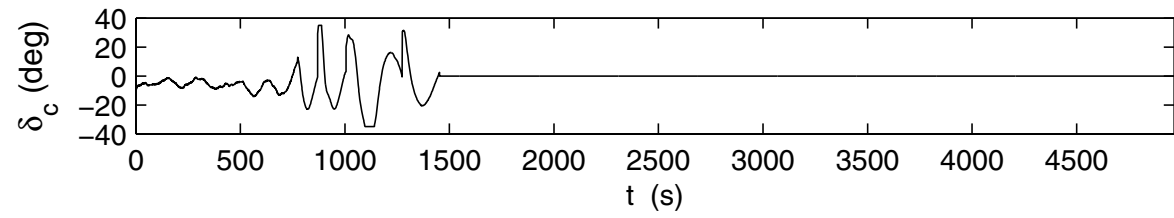

Fig. 10. Experimentally recorded commanded inputs for thrusters. Plot (a) shows operating modes of the supervisory controller, and the other plots show commanded relative propeller revolutions for the bow tunnel thruster $p_{2 c}(\mathrm{~b})$, commanded relative propeller revolutions for the stern tunnel thruster $p_{3 c}(\mathrm{c})$, commanded main propeller revolutions $n_{1 c}$ (d), commanded rudder angle $\delta_{c}(\mathrm{e})$.

Davidson, K.S.M. and Schiff, L.I., (1946). Turning and course keeping qualities, Transactions of the Society of Naval Architects Marine Engineers 54: 152-190.

Fossen, T.I. (2011). Handbook of Marine Craft Hydrodynamics and Motion Control, John Wiley \& Sons, Chichester.

Gelb, A. (1974). Applied Optimal Estimation, MIT Press, Cambridge, MA.

Gierusz, W. (2001). Simulation model of the shiphandling training boat Blue Lady, Proceedings of the 5th IFAC Conference on Control Application in Marine Systems (CAMS), Glasgow, UK.

Godhavn, J.M., Lauvdal, T. and Egeland, O. (1996). Hybrid control in sea traffic management systems, in R. Alur et al. (Eds.), Hybrid Systems III, Springer, New York, NY, pp. 149-160.

Goedel, R., Sanfelice, R.G. and Teel, A.R. (2012). Hybrid Dynamical Systems: Modeling Stability, and Robustness, Princeton University Press, Princeton, NJ.

Hespanha, J.P. (2001). Tutorial on supervisory control, 40th IEEE Conference on Decision and Control, Orlando, FL, USA.

Holzhüter, T. (1990). A high precision track controller for ships, Proceedings of the 11th IFAC World Congress, Tallin, Estonia, pp. 118-123.
Iława (2016). Ship Handling Research and Training Centre, Iława, Poland, http://www.ilawashiphandling.com.pl

Kamgarpour, M., Soler, M., Tomlin, C., Olivares, A. and Lygeros, J. (2011). Hybrid optimal control for aircraft trajectory design with a variable sequence of modes, Preprints of the 18th IFAC World Congress, Milan, Italy, pp. 7238-7243.

Kurt, A. and Özgüner, Ü. (2013). Hierarchical finite state machines for autonomous mobile systems, Control Engineering Practice 21(2): 184-194, DOI: 10.1016/j.conengprac.2012.09.020.

Lisowski, J. (2013). Sensitivity of computer support game algorithms of safe ship control, International Journal of Applied Mathematics and Computer Science 23(2): 439-446, DOI: 10.2478/amcs-2013-0033.

Lygeros, J., Godbole, D.N. and Sastry, S. (1996). Verified hybrid controllers for automated vehicles, IEEE Transactions on Automatic Control 43(4): 522-539, DOI: $10.1109 / 9.664155$.

Nguyen, T.D., Sorensen, A.J. and Quek, S.T. (2007). Design of hybrid controller for dynamic positioning from calm to extreme sea conditions, Automatica 43(5): 768-785, DOI: 10.1016/j.automatica.2006.11.017. 
a)

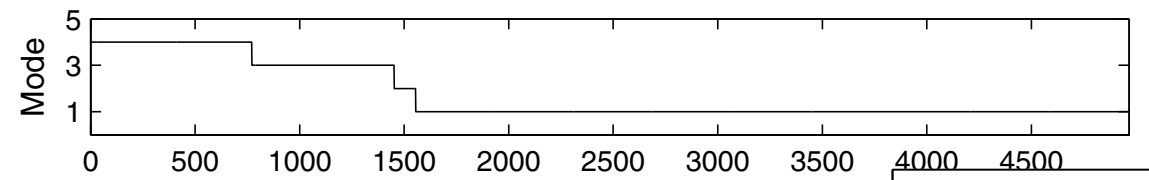

b)

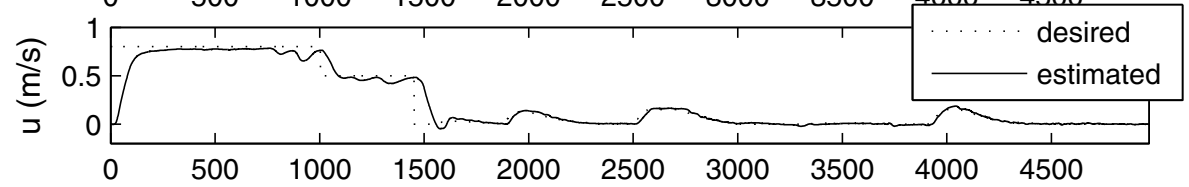

c)

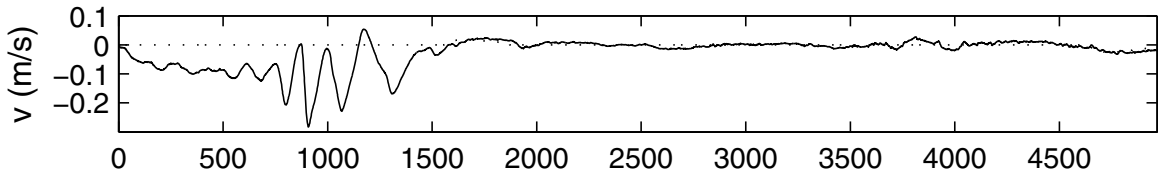

d)

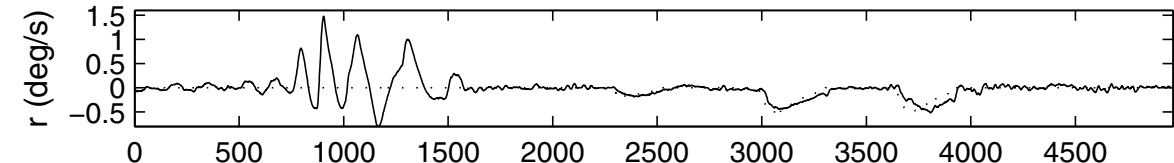

e)

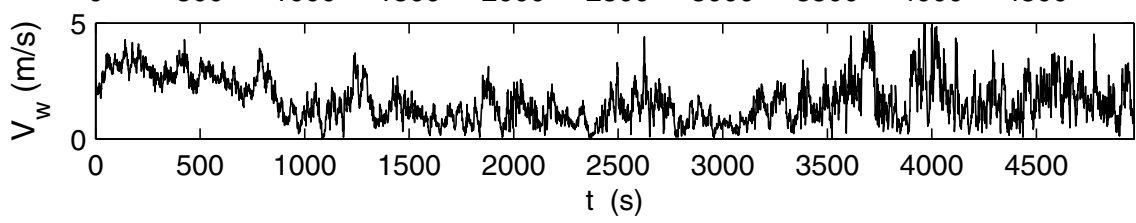

Fig. 11. Experimentally recorded speeds. Plot (a) shows operating modes of the supervisory controller. Plots (b)-(d) show the desired and estimated velocities in surge $u$, sway $v$ and yaw $r$. Plot (e) shows the measured relative wind speed $V_{w}$.

Nguyen, T.D., Sorensen, A.J. and Quek, S.T. (2008). Multi-operational controller structure for station keeping and transit operations of marine vessels, IEEE Transactions on Control Systems Technology 16(3): 491-498, DOI: $10.1109 /$ TCST.2007.906309.

Nguyen, T. D. and Sorensen, A. J. (2009). Switching control for thruster-assisted position mooring, Control Enginering Practice 17(9): 985-994, DOI: 10.1016/j.conengprac.2009.03.001.

Nomoto, K., Taguchi, T., Honda, K. and Hirano, S. (1957). On the steering qualities of ships: Technical Report, International Shipbuilding Progress 4(35): 354-370.

Pomirski, J., Rak, A. and Gierusz, W. (2012). Control system for trials on material ship model, Polish Maritime Research 19(S1): 25-30.

Pritchett, A.R., Lee, S.M. and Goldsman, D. (2001). Hybrid-system simulation for national airspace system safety analysis, Journal of Aircraft 38(5): 835-840, DOI: $10.2514 / 2.2868$

Salehi, R, Shahbakhti, M. and Hedrick, J.K. (2014). Real-time hybrid switching control of automotive cold start hydrocarbon emission, Journal of Dynamic Systems, Measurement, and Control 136(4): 041002-041002-10, DOI: $10.1115 / 1.4026534$.

Smogeli, O.N., Sorensen, A.J. and Fossen, T.I. (2004). Design of a hybrid power/torque thruster controller with thrust loss estimation, Proceedings of the IFAC Conference on Control Application in Marine Systems (CAMS), Ancona, Italy, pp. 409-414.

Taghavipour, A., Azad, N.L. and McPhee, J. (2015). Real-time predictive control strategy for a plug-in hybrid electric powertrain, Mechatronics 29(8): 13-27, DOI: 10.1016/j.mechatronics.2015.04.020.

Tomera, M. (2010). Discrete Kalman filter design for multivariable ship motion control: Experimental results with training ship, Joint Proceedings of Gdynia Martime University and Hochschule Bremerhaven: 26-34.

Tomera, M. (2014). Dynamic positioning system for a ship on harbour manoeuvring with different observers: Experimental results, Polish Maritime Research 21(3): 3-24, DOI: 10.2478/pomr-2014-0025.

Tomera, M. (2015). A multivariable low speed controller for a ship autopilot with experimental results, Proceedings of the 20th International Conference on Methods and Models in Automation and Robotics (MMAR), Międzyzdroje, Poland, pp. 17-22, DOI: 10.1109/MMAR.2015.7283699.

Tutturen, S.A. and Skjetne, R. (2015). Hybrid control to improve transient response of integral action in dynamic positioning of marine vessels, IFAC-PapersOnLine 48(16): 166-171, DOI: 10.1016/j.ifacol.2015.10.275.

Xiang, Z., Wang, R. and Chen, Q. (2010). Fault tolerant control of switched nonlinear systems with time delay under asynchronous switching, International Journal of Applied 
Mathematics and Computer Science 20(3): 497-506, DOI: 10.2478/v10006-010-0036-0.

Yang, H., Jiang, B., Cocquempot, V. and Lu, L. (2012). Supervisory fault tolerant control with integrated fault detection and isolation: A switched system approach, International Journal of Applied Mathematics and Computer Science 22(1): 87-97, DOI: 10.2478/v10006-012-0006-9.

Zhang, F., Zhai, Y., Liao, J. (2016). A new sufficient schedulability analysis for hybrid scheduling, International Journal of Applied Mathematics and Computer Science 26(3): 683-692, DOI: 10.1515/amcs-2016-0047.
Mirosław Tomera received the MSc degree in control engineering in 1990 and the PhD degree in ship automation in 2001 from the Gdańsk University of Technology. Currently he is an assistant professor at the Department of Ship Automation, Gdynia Maritime University. His main scientific interests include computer control of dynamic systems, ship autopilots, dynamic positioning systems, state estimators for marine vessels and hybrid control systems for ships.

Received: 10 April 2016

Revised: 17 October 2016

Re-revised: 25 November 2016

Accepted: 17 December 2016 